ARTICLE

\title{
Savoring mediates the effect of nature on positive affect
}

\author{
Izuru Sato · Paul E. Jose - Tamlin S. Conner
}

\begin{abstract}
The more time people spend in nature, the happier they feel. But how consistent is this link, and what mechanisms might account for this beneficial effect of nature on wellbeing? The aim of the present study was to test one potential mechanism linking nature to wellbeing - the ability to savor experiences. Participants ( $N=60,70 \%$ female, aged 18 to 34 , university students) were randomly assigned to take a daily 20-minute walk in a natural or urban environment for seven consecutive days. Each night, they completed a daily diary report about their experiences that day, including the amount and types of their savoring during the walk (i.e., absorption and intensification of experiences), savoring after the walk (i.e., expression of gratitude and sharing their experiences with others) all adapted from the Ways of Savoring Checklist (Bryant \& Veroff, 2007), and their daily feelings of positive affect (PA) and negative affect (NA), adapted from the affective circumplex (Barrett \& Russell, 1998). Path analyses using multi-level structural equation modeling (MSEM) found that the composite measure of daily savoring significantly mediated the effect of nature on PA, controlling for NA and physical activity. Daily exposure to nature contributed to greater daily savoring, which predicted higher daily PA. Additional analyses showed that absorption and intensification of experiences in nature and sharing nature experiences with others were the key components of savoring, which may help to explain why people feel happier as a result of spending time in nature.
\end{abstract}

Keywords: emotion regulation, savoring, nature, wellbeing, positive affect, MSEM, diary study

\section{Savoring mediates the effect of nature on positive affect}

There is growing awareness of the psychological benefits of interacting in natural environments like gardens, forests, parks, and green spaces. These benefits include reduced stress (Grahn \& Stigsdotter, 2003; Pasanen, Neuvonen, \& Korpela, 2017), lower fatigue (Korpela, Ylen, Tyrvainen, \& Silvennoinen, 2010; Stigsdotter et al., 2010), better mood (Passmore \& Howell, 2014), and greater happiness (MacKerron \& Mourato, 2013). Although initial research focused on the relationship between nature and reduced ill-being (e.g., reductions in stress; Grahn \& Stigsdotter, 2003), contemporary research has found even stronger relationships between nature and heightened wellbeing, in particular, improvements in positive affect (PA) (e.g., Barton \& Pretty, 2010; Bowler, Buyung-Ali, Knight, \& Pullin, 2010; Bratman, Daily, Levy, \& Gross, 2015; Frumkin, 2001; Hartig, Evans, Jamner, Davis, \& Garling, 2003; Kuo, 2015; McMahan \& Estes, 2015; Maller, Townsend, Pryor, Brown, \& St Leger, 2006). In fact, a meta-analysis of studies comparing the effects of exposure to natural environments versus exposure to urban or built environments showed a much stronger effect of natural environments on PA (average $r=0.31 ; 95 \%$ CI 0.24 , 0.37 ) than NA (average $r=-0.12 ; 95 \%$ CI $-0.17,-0.07$ ) (McMahan \& Estes, 2015).

What is the mechanism by which experiences with nature improve PA? Previous research has focused mainly on the role of cognitive factors to explain the beneficial effects of nature. For 
example, attention restoration theory (ART) (Kaplan \& Kaplan, 1989; Kaplan, 1995) posits that natural environments possess certain visual and acoustic features that evoke the experiences of "fascination" whereby our attention is drawn to interesting stimuli that engage attention without overloading attentional capability (Berto, 2005; Kaplan, 1995). In everyday life, conscious effort is required to attend to many stimuli and tasks at once, which can eventually tax attentional resources. Evidence shows that fascinating stimuli in nature can provide the mental opportunity to restore depleted attentional resources, and, as a result, induce positive emotions in people (e.g., Berto, 2014; Berto, 2005; Kaplan \& Kaplan, 1989; Sato \& Conner, 2013). This may be due to the fractal features of objects in natural environments (e.g., trees/flowers/plants), which are particularly relaxing (van den Berg, Joye, \& Koole, 2016) and visually/aesthetically preferred (Spehar, Clifford, Newell, \& Taylor, 2003; Spehar \& Taylor, 2013). In addition, it has been suggested that natural environments evoke a type of perceptual fluency that can promote PA (Joye \& van den Berg, 2011). However, mechanisms related to positive emotion regulation, such as savoring, might also explain the beneficial effects of experiencing nature on PA.

Savoring is the process by which individuals actively use strategies to enhance and prolong positive experiences (e.g., Bryant \& Veroff, 2007; Quoidbach, Berry, Hansenne, \& Mikolajczak, 2010). Savoring involves various strategies that people can use during or after positive experiences such as 1) being in the present moment (experiential absorption), 2) intensifying one's experiences by focusing on them (sensory-perceptual sharpening), 3) gratitude making (counting blessings), and 4) sharing these experiences with others (sharing with others) (Bryant, Chadwick, \& Kluwe, 2011; Bryant \& Veroff, 2007; Jose, Lim, \& Bryant, 2012). Through these four broad savoring strategies, people can derive greater positive affect from everyday events and experiences (Jose et al., 2012). For example, Jose and colleagues tracked the daily experiences of young adults $(\mathrm{N}=101)$ for 30 days and found that daily positive events were associated with daily happiness, and that daily savoring accounted for the link between positive events and happiness (Jose et al., 2012). Unlike the stress-coping process, which deals with negative emotion regulation (Lazarus \& Folkman, 1984), savoring puts a special focus on positive coping, which emphasizes various strategies to enhance positive experiences (Bryant \& Veroff, 2007). Past research has shown that savoring as a form of positive coping is effective at enhancing pleasurable feelings (Bryant et al., 2011; Bryant \& Smith, 2015; Gentzler, Palmer, \& Ramsey, 2015; Quoidbach et al., 2010; Quoidbach, Mikolajczak, \& Gross, 2015).

Savoring strategies fit within larger process models of emotion regulation (Gross \& Thompson, 2007; Quoidbach et al., 2015). As shown in Table 1 below, these models typically recognize five stages of emotion regulation: situation selection, situation modification, attentional deployment, cognitive change, and response modulation (Gross, 2015; Gross \& Thompson, 2007). Strategies in each stage have the potential to intensify, dampen, or maintain positive emotion (Gross, 2015; Quoidbach et al., 2015). Savoring strategies such as experiential absorption and sensory-perceptual sharpening are both forms of attentional deployment, where attention is deployed strategically to maximize positive emotions. Counting blessings is a form of cognitive change, which involves a cognitive reappraisal to appreciate positive experiences. Sharing the experiences with others is a form of response modulation, which involves behavioral activation to make the best of positive experiences. 
Table 1. How savoring fits into the process model of positive emotion regulation (adapted from Bryant \& Veroff, 2007; Quoidbach et al., 2015)

\begin{tabular}{|c|c|c|c|c|c|}
\hline & \multicolumn{5}{|c|}{ The Five Stages of Positive Emotion Regulation } \\
\hline & $\begin{array}{l}\text { Situation } \\
\text { selection }\end{array}$ & $\begin{array}{l}\text { Situation } \\
\text { modification }\end{array}$ & $\begin{array}{l}\text { Attentional } \\
\text { deployment }\end{array}$ & $\begin{array}{l}\text { Cognitive } \\
\text { change }\end{array}$ & $\begin{array}{l}\text { Response } \\
\text { modulation }\end{array}$ \\
\hline Savoring & & & $\begin{array}{l}\text { Experiential } \\
\text { absorption; } \\
\text { Sensory- } \\
\text { perceptual } \\
\text { sharpening }\end{array}$ & $\begin{array}{l}\text { Counting } \\
\text { blessings }\end{array}$ & $\begin{array}{l}\text { Sharing with } \\
\text { others }\end{array}$ \\
\hline Example & $\begin{array}{l}\text { Decide to } \\
\text { go to a park }\end{array}$ & $\begin{array}{l}\text { Walk around } \\
\text { the best } \\
\text { spots } \\
\text { possible in } \\
\text { the park }\end{array}$ & $\begin{array}{l}\text { Immerse } \\
\text { yourself in the } \\
\text { walking } \\
\text { experience; } \\
\text { Focus on the } \\
\text { park's natural } \\
\text { features }\end{array}$ & $\begin{array}{l}\text { Find the } \\
\text { positive } \\
\text { aspects of } \\
\text { the nature } \\
\text { experience }\end{array}$ & $\begin{array}{l}\text { Share with } \\
\text { others/express } \\
\text { the joy }\end{array}$ \\
\hline
\end{tabular}

In this article, we propose that the context of natural environments might stimulate the enactment of savoring strategies more so than urban environments, which could help account for the nature-PA link documented by other researchers. Natural environments are perceived as more favorable places than urban ones (Korpela, Hartig, Kaiser, \& Fuhrer, 2001) and so people might be more likely to try to savor their experiences as a form of positive coping in natural environments. Natural environments are thought to stimulate humans' evolved tendencies towards "biophilia," which is posited as an innate affiliative tendency to seek out natural environments and features that provide an advantageous evolutionary ecological niche (Kellert \& Wilson, 1995; Wilson, 1984). Being in nature might trigger various savoring strategies implemented to satisfy and prolong this affiliative tendency, which could, in turn, result in increased positive affect.

We are aware of only two studies linking experiences with nature to a form of savoring (Johnsen \& Rydstedt, 2013; Richardson \& Sheffield, 2017). In Johnsen and Rydstedt's (2013) laboratory study, participants $(N=473)$ were presented with photos of natural and urban environments, then rated the degree to which they would seek out each environment if they were happy. On average, participants reported that they would want to seek out natural but not urban environments when they felt happy. Thus, seeking nature could be considered a situation selection strategy to savor and prolong their positive state. In Richardson and Sheffield's (2017) field experiment $(N=92)$, savoring of nature was manipulated by asking half of the participants to "write three good things in nature that you noticed today" for five days, which is equivalent to counting blessings. Control participants noted three factual things for the same amount of time. Those who were asked to write about good things in nature (versus factual things) showed improvements in connectedness to nature, which predicted some improvements in mental health as measured by the 12-item General Health Questionnaire (Goldberg \& Hillier, 1979). Although the findings of Richardson and Sheffield (2017) suggest that a brief manipulation to promote savoring of nature is beneficial, it does not establish whether people would naturally savor their time in nature on their own volition. The question remains whether experiences in nature promote the key specific savoring strategies that occur when people experience nature (such as 
experiential absorption and sensory-perceptual sharpening) or after people experience nature (like counting blessings, and sharing the experience with others), and whether these savoring strategies account for the improvements in PA. Thus, our study was designed to fill this gap by testing whether natural (versus urban) environments are more likely to promote daily savoring strategies, and whether daily savoring mediates the expected beneficial effect of nature on PA.

\subsection{The present study}

We employed a week-long experimental daily diary study in which participants were randomly assigned to take a daily 20-minute walk in either a natural or an urban setting, and to report nightly their various experiences of savoring, and to rate their level of positive and negative affect and amount of physical activity engaged in outside of the assigned walk. Negative affect (NA) and extra physical activity were used as control variables in analyses. Analyses examined if daily savoring mediated the effect of natural (vs. urban) environments on daily PA. As an exploratory analysis, we also tested what types of savoring might function as mediators.

\section{Method}

\subsection{Design}

This daily experimental design included both between- and within-subjects components. The between-subjects component was the experimental manipulation (daily nature walk versus daily urban walk as control). The within-subjects component included the variables assessed in the daily diary survey completed each evening across the seven days (i.e., savoring, PA, NA, physical activity).

\subsection{Participants}

Participants were 60 young adults (18 males and 42 females) with a mean age of $21.72(S D=3.76$; range 18 -34) who were students at the University of Otago in Dunedin, New Zealand. An additional two participants started the study but were excluded from analysis (one participant dropped out because of sickness during the experiment; one participant completed fewer than four diary records). Participants identified as European (73.3\%), Asian (20.0\%), or another ethnicity (6.7\%). Participants were recruited for the "Daily Walk Study" conducted in Dunedin, New Zealand between February and April 2015, which corresponded to the end of summer and the beginning of fall. Participants were required to have nightly access to internet via smartphone or computer ( $n=0$ excluded). Participants were reimbursed with research credits if recruited through the University of Otago Psychology Department's experimental participation program $(n=34,57 \%)$ or with $\$ 20$ if recruited through flyers/word of mouth $(n=26,43 \%)$.

\subsection{Procedure}

Each participant attended an initial individual briefing session on campus where the study procedures were explained and the informed consent was read and signed. Participants were then asked to fill out an initial online questionnaire, either immediately using their smartphone, or later that night on their computer. This initial questionnaire contained demographic questions (i.e., age, gender, ethnic background) followed by written instructions for their randomly assigned condition. Participants in the nature condition were instructed to take a daily 20-minute walk alone in the Dunedin Botanic Gardens beginning the next day for seven days. The Dunedin Botanic Gardens is a 75-acre (30.4 hectare) space located within walking distance to the university and central shopping/business district. The grounds are beautifully cultivated with over 6,800 
plant species including native New Zealand trees, grasses, and flowers, among other plants from around the world. There are paved and unpaved walking paths winding through both flat and hilly terrain. Participants in the urban condition were instructed to take a daily 20-minute walk alone in an adjacent urban environment (along George Street in the central shopping/business district) beginning the next day for seven days. George Street is a busy 1.2 mile (2 km) street full of shops and restaurants that is located within walking distance to the university. The street has sidewalks for pedestrians and is open to cars and buses (18.6 mph max speed / 30km max speed). Participants were allowed to take their daily walk whenever they saw fit during the daytime period. Each evening during the intervention week, participants were prompted via email to fill out an online daily diary survey using either their smartphone or computer. The email reminder was sent at $7 \mathrm{pm}$; the survey was available for participants to complete until midnight. In the survey, participants indicated if they completed their walk that day (yes/no), and answered questions regarding their experiences from the day (i.e., savoring, PA, and NA, physical activity). After repeating the daily procedure for seven consecutive days, participants were individually debriefed about the study aims and reimbursed for their participation.

\subsection{Daily Measures}

Savoring. Participants' experiences of savoring were measured using the four-item "momentary savoring" scale (Jose et al., 2012), which was taken from a subset of items from Bryant and Veroff's (2007) Ways of Savoring Checklist. The four items were: 1) "I thought only about the present - got absorbed in the moment" (experiential absorption), 2) "I tried to intensify the moment by focusing on it" (sensory-perceptual sharpening), 3) "I felt grateful for the pleasant event(s)" (counting blessings), and 4) "I tried to share the positive aspects with another person" (sharing with others). Participants rated items 1 (experiential absorption) and 2 (sensoryperceptual sharpening) with regards to how they felt during the walk. Participants also rated items 3 (counting blessings) and 4 (sharing with others) with regards to how they felt after the walk. Each of the four items was rated using a five-point Likert scale $(1=$ not at all, $5=$ extremely $)$. Three variables were created from these items: an overall savoring variable (mean of all four items), a savoring during the walk variable (mean of experiential absorption and sensory-perceptual sharpening), and a savoring after the walk variable (mean of counting blessings and sharing with others). See Table 2 below for measure reliabilities.

Positive and negative affect. Participants' affective experiences were measured using three items for positive affect (PA) (enthusiastic, happy, relaxed) and three items for negative affect (NA) (angry, anxious, sad). These items captured a range of high to low intensities from the affective circumplex (Barrett \& Russell, 1998). Participants were asked to rate how they felt "that day" on each of the six items using a five-point Likert scale $(1=$ not at all, $5=$ extremely). Responses to the three positive affect and the three negative affect items were averaged for a measure of positive affect (PA) and negative affect (NA). See Table 2 below for measure reliabilities. NA was used as a control variable to isolate the effects of natural environments on PA. We used NA as a control variable rather than creating a composite measure such as net PA (PA minus NA) because our prior research found that nature interventions change PA independently from NA (Sato \& Conner, 2013). Subtracting NA from PA could potentially obscure the patterns for PA.

Daily physical activity. As an additional control measure, a measure of daily physical activity (aside from the assigned walk) was included in the daily diary. Participants were asked to freely report "How many minutes did you spend doing vigorous and moderate physical activities besides the walk today?" 


\section{Results}

\subsection{Psychometrics and descriptive statistics}

Most participants completed all seven daily diary entries (99\% response rate; $M=6.92 ; S D=0.38$; range 5 to 7). They reported taking their walk on almost all days (walking 413 out of 420 requested days; $98 \%$ compliance). Of the 60 participants, 30 participants were randomized into the nature group, and 30 participants were randomized into the urban group. Chi-square tests revealed that both gender and ethnicity were equally distributed across the two groups (gender $\gamma^{2}(1,60)=0.32 ; p=.57$; ethnicity $\left.\gamma^{2}(2,60)=0.42 ; p=.81\right)$. Diary response rates were also similar between the two groups $(t(418)=1.14, p=.25)$.

The reliabilities of each daily measure were estimated at both levels (between-person and within-daily) using the method recommended by Geldhof, Preacher, and Zyphur (2014). A multilevel confirmatory factor analyses (MCFA) approach was used to estimate between- and within-level Cronbach's alpha $(\alpha)$ separately by using MCFA model parameters directly. Multilevel $\alpha$ was computed in Mplus software version 7.31 (Muthén \& Muthén, 2012). The reliability estimates indicated that the item reliabilities were good at the between-person level, ranging from .823 to .944 , and were lower but still acceptable at the within-person level, ranging from .555 to .716 . The observed reliability at both levels indicated that it was appropriate to use these measures in both the between- and within-person analyses. See Table 2 below for complete item descriptive statistics and reliabilities across levels.

Table 2. Descriptive statistics and multilevel reliability estimates for the daily measures

\begin{tabular}{lcrrrrc}
\hline & & & & & \multicolumn{2}{c}{ Reliability Estimate } \\
\cline { 6 - 7 } Daily Variable & $\boldsymbol{M}$ & \multicolumn{1}{c}{$\boldsymbol{S D}$} & Min & Max & (Between) & (Within) \\
\hline Savoring & 2.72 & 0.86 & 1.04 & 4.89 & .944 & .716 \\
Positive Affect & 3.16 & 0.56 & 1.57 & 4.43 & .883 & .691 \\
Negative Affect & 1.77 & 0.49 & 1.00 & 3.24 & .823 & .555 \\
Physical Activity & 28.78 & 22.93 & 0.00 & 111.43 & n/a & n/a \\
\hline
\end{tabular}

Note. $\mathrm{M}=$ Mean, $\mathrm{SD}=$ Standard Deviation, $\mathrm{Min}=$ Minimum, Max = Maximum

Table 2 also presents the descriptive statistics for the aggregated daily variables. Daily PA yielded a higher mean than NA, which is typical. All variables showed sufficient variability and range.

Table 3 below presents the zero order correlations among the experimental conditions and the aggregated daily measured variables. The nature (vs. urban) condition was associated with greater savoring. As expected, participants in the nature condition reported higher average levels of savoring compared to participants in the urban condition. Contrary to our expectation, however, we found no significant association between the nature condition and PA (total effect $r=.083, p=.528)$. Other physical activity was not significantly associated with any of the other variables. 
Table 3. Correlations between the experimental conditions and aggregated daily variables

\begin{tabular}{lcccc}
\hline & $\begin{array}{c}\text { Condition } \\
\text { Nature }=\mathbf{1} \\
\text { Urban }=\mathbf{0}\end{array}$ & Savoring & $\begin{array}{c}\text { Positive } \\
\text { Affect }\end{array}$ & Negative Affect \\
\hline Condition $^{\mathrm{a}}$ & - & & & \\
Savoring & $\mathbf{3 6 0 ^ { * * }}$ & - & & \\
Positive Affect & .083 &. $\mathbf{5 8 7 ^ { * * }}$ & - & - \\
Negative Affect & -.078 & -.021 & $-.265^{*}$ & -.138 \\
Physical Activity & .003 & .027 & .150 & \\
\hline
\end{tabular}

Note. $N=60 .{ }^{*} p<.05 ;{ }^{* *} p<.01$.

\subsection{Multi-level Mediation Analysis}

The unique feature of this daily experimental design required special consideration when analyzing mediation within nested data sets (multiple reports nested within individuals). As Figure 1 shows, the independent variable ( $\mathrm{X}$ - nature vs. urban) was manipulated at the betweenperson level (level 2) whereas the mediator ( $\mathrm{M}$ - savoring) and outcome variable ( $\mathrm{Y}-\mathrm{PA}$ ) were assessed at the within-person daily level (level 1).

Figure 1. Multi-level mediation model framework (2-1-1 model with a random level-1 effect); adapted from Preacher et al. (2011).

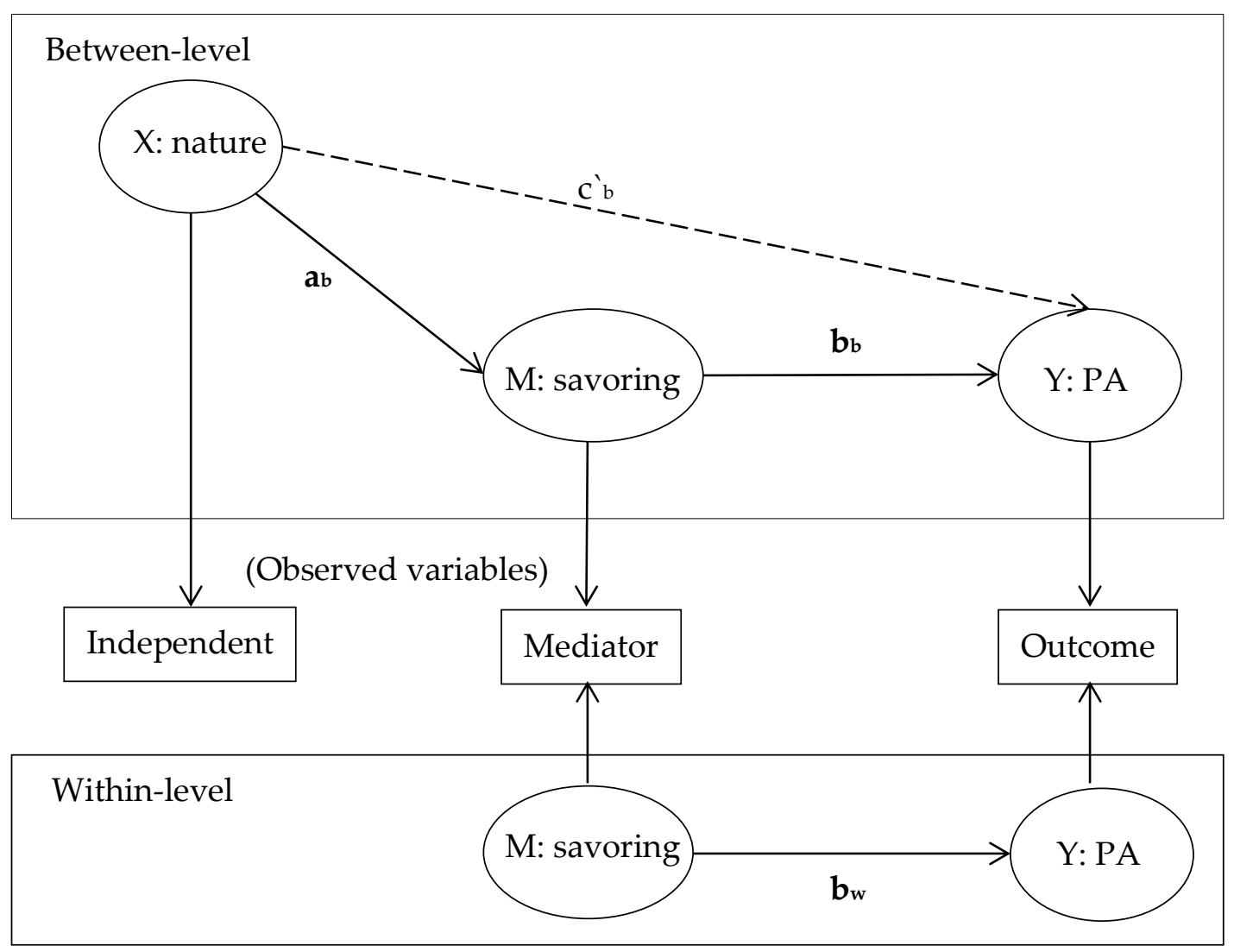

Note. $\mathrm{X}=$ independent variable, $\mathrm{M}=$ mediator variable, $\mathrm{Y}=$ outcome variable. $\mathrm{PA}=$ positive affect 
This type of structure is called a "2-1-1 design" (Preacher, Zyphur, \& Zhang, 2010). In a 2-1-1 design, $X$ (nature) varied only between people (individuals assigned to the nature group) whereas both M (savoring) and Y (PA) varied at both the between- and within-person levels. This design specifies that people will differ from each other in their average levels of $\mathrm{M}$ (savoring) and $Y(P A)$, and individuals will differ across time at the within-person level in $\mathrm{M}$ (savoring) and $Y(P A)$. These sources of variance needed to be taken into account appropriately.

To address this issue, multi-level structural equation modeling (MSEM) was conducted for estimating indirect effects (Preacher, Zhang, \& Zyphur, 2011; Preacher et al., 2010), instead of using Baron and Kenny's stepwise method (Baron \& Kenny, 1986; Card, 2012; Jose, 2013) with a Sobel test (Sobel, 1982). Specifically, we used Mplus software version 7.31 (Muthén \& Muthén, 2012) to test whether savoring mediated the relationship between nature and PA for participants in the nature (versus urban) condition, controlling for NA and physical activity. Although there was no total effect of nature on PA overall (total effect $r=.083$, ns, as above), the recent literature on mediation analyses has indicated that the total effect of an independent variable on a dependent variable is no longer required when computing all steps simultaneously, and each constituent path is significant (independent variable to mediation variable (a path); and mediation variable to dependent variable (b path)) (MacKinnon \& Fairchild, 2009; Preacher, 2015).

Computationally, the multilevel mediational model was defined as a 2-1-1 model in which the predictor ("nature" coded as 1 vs. "urban" coded as 0) was assessed at level 2 (betweenperson level), whereas the potential mediator (savoring) and outcome (PA) were assessed at level 1 (within-person daily level). The equation for this particular multilevel mediation model is as follows:

Level 1:

$\begin{array}{ll}\text { Savoring }_{i j}=\beta_{\text {Savoring }}+\varepsilon_{i j} & \text { Equation 1 } \\ P A_{i j}=\beta_{P A j}+b_{w j} \text { Savoring }+\varepsilon_{i j} & \text { Equation 2 }\end{array}$

Level 2:

$\beta_{\text {Savoringj }}=\gamma_{\text {Savoring }}+a$ Nature $_{j}+\mu \beta_{\text {Savoringj }}$

Equation 3

$\beta P A_{j}=\gamma_{P A}+c^{\prime}$ Nature $_{j}+b_{b} \beta_{\text {Savoringj }}+\mu \beta_{P A j}$

Equation 4

$b_{w j}=b_{w}+\mu_{b w j}$

Equation 5

For these equations, the level 1 model is an intercept for Savoring (Eq. 1) and an intercept for PA plus a within-person effect of Savoring on PA (Eq. 2). The level 2 model estimates a random Savoring intercept from Nature (a mean difference, path a) (Eq. 3), a random PA intercept from level 2 Nature (an adjusted mean difference and the direct effect of Nature, path c'), and the Savoring intercept for level 2, unit j (a between-person effect of Savoring on PA, path bbetw) (Eq. 4), and allows the within-daily effect of Savoring on PA to vary between person (path $b_{\text {with }}$ ) (Eq. 5). Following the method recommended by Preacher et al. (2010), a Monte Carlo procedure was used to estimate multilevel indirect effects in the 2-1-1 model. We predicted a positive indirect effect of nature on PA through savoring.

Results from the multilevel mediational model showed that, as predicted, daily savoring significantly mediated the pathway between the nature condition and PA. This result is demonstrated by the indirect effect being significant and the $95 \%$ confidence intervals (CI) of that effect not spanning zero. This effect remained significant even after controlling for daily physical activity and NA (see Table 4 for pathway coefficients). 
Table 4. Unstandardized path coefficients and $95 \%$ confidence intervals for indirect effects of the multilevel mediation model

\begin{tabular}{lllllccc}
\hline Predictor & Mediator & Outcome & Path $a$ & Path $\boldsymbol{b}$ & $\begin{array}{c}\text { Indirect } \\
\text { Effect }\end{array}$ & \multicolumn{2}{c}{$\mathbf{9 5 \%}$ CI } \\
(Lower) & (Upper) \\
\hline $\begin{array}{l}\text { Nature } \\
\text { vs. Urban }\end{array}$ & Savoring & $\begin{array}{l}\text { Positive } \\
\text { Affect }\end{array}$ & $\mathbf{. 6 7 7}^{* *}$ & $\mathbf{1 . 0 0 8}^{* *}$ & $\mathbf{. 6 8 2 ^ { * * }}$ & .456 & .908 \\
\hline
\end{tabular}

Note. The path $a$ coefficient represents the path between the predictor and mediator, and the path $b$ coefficient represents the path between the mediator and the outcome. The indirect effect coefficient represents the effect of the predictor on the outcome via the mediator $\left(a^{*} b\right)$. The $95 \%$ confidence interval (CI) represents the lower and upper boundaries of the estimated indirect effect of the predictor on the outcome via the mediator. ${ }^{* *} p<.01$. (Significant effects are bolded.)

Additional mediational analyses were conducted, separating the savoring construct into savoring during the walk (experiential absorption and sensory-perceptual sharpening), and savoring after the walk (counting blessings and sharing with others) to determine whether savoring during or after the walk was the stronger predictor of PA. As Figure 2 shows, when both forms of savoring were included in the model, only savoring after the walk survived as a mediator of the nature-PA link $(\beta=0.803, p=.04)$.

Figure 2. Multiple mediation analysis testing savoring during the walk and savoring after the walk separately

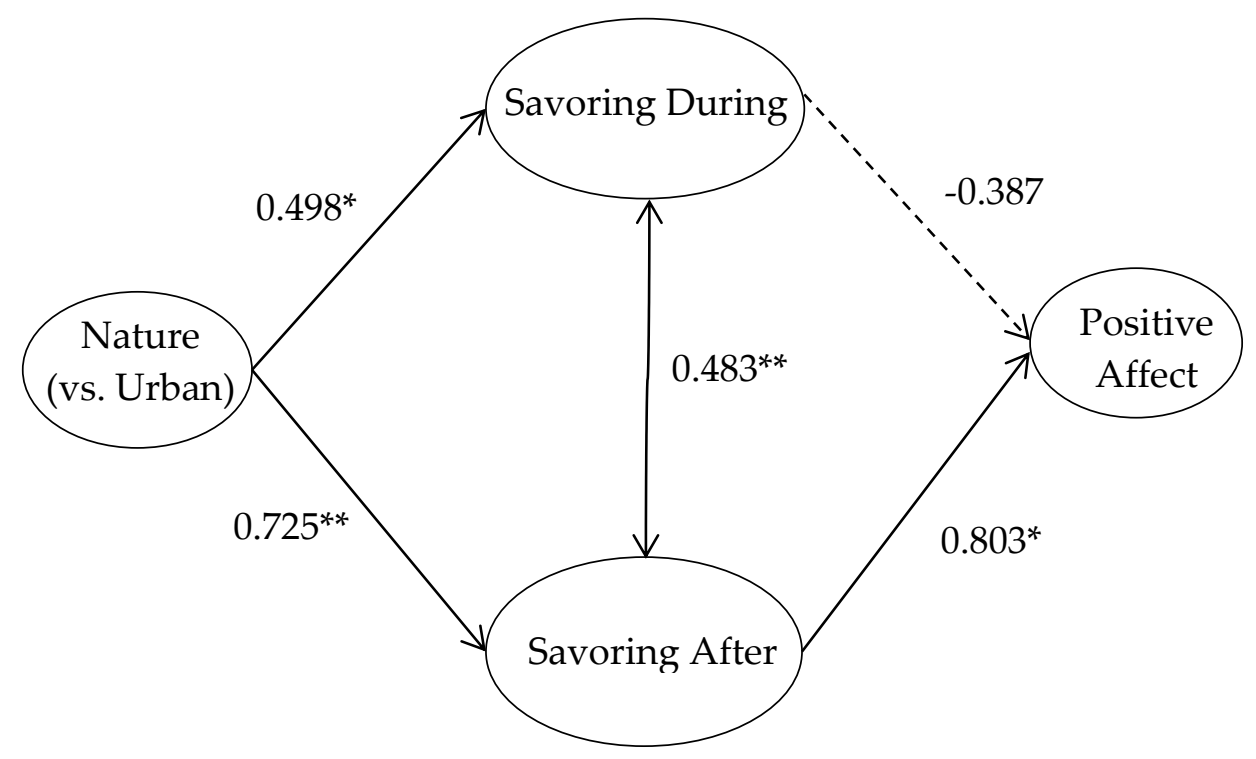

Note. Unstandardized path/correlation coefficient; ${ }^{*} p<.05 ;{ }^{* *} p<.01$.

Interestingly, savoring during the walk was negatively associated with PA, albeit nonsignificantly $(\beta=-0.387, p=.33$ ). Although this pattern could indicate a paradoxical effect whereby greater absorption and focus within natural environments might dampen positive feelings, it could indicate that savoring during the walk is ineffective at increasing PA without additional savoring after the walk. In fact, when the temporal sequencing of savoring was taken into account (savoring during the walk predicting savoring after the walk) in the form of a double mediation (see Jose, 2013), both forms of savoring were found to be important. Figure 3 presents 
this temporally-refined path model in which savoring during the nature walk predicted greater savoring after the walk, which, in turn, predicted higher PA.

Figure 3. Double mediation path model, taking into account the temporal sequence of nature (vs. urban) walking predicting savoring during the walk, then savoring after the walk, which predicted PA

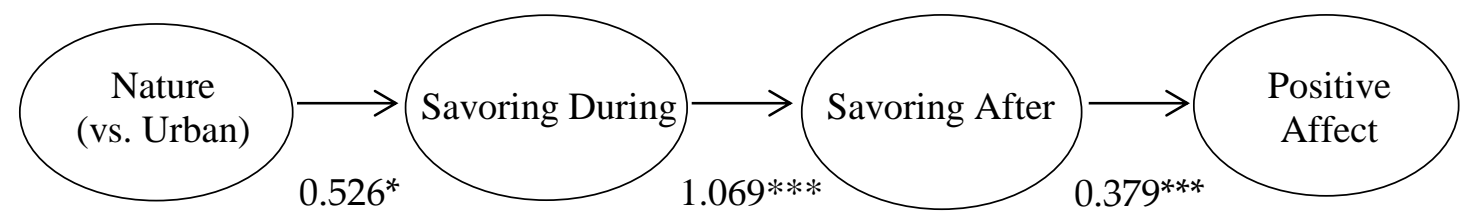

Note. Unstandardized path/correlation coefficient; ${ }^{*} p<.05 ;{ }^{* *} p<.01 ;{ }^{* * *} p<.001$.

This multilevel path model showed good to excellent fit with the data: a comparative fit index $(\mathrm{CFI})=0.957$, Tucker-Lewis index $(\mathrm{TLI})=0.911$, root-mean-square error of approximation $($ RMSEA $)=0.067$, standardized root mean square residual $($ sRMR $)$ for between $=0.055$, sRMR for within $=0.031($ Kline, 2011) .

Figure 4. Multiple mediator analysis separating the four savoring items (all four mediators entered simultaneously)

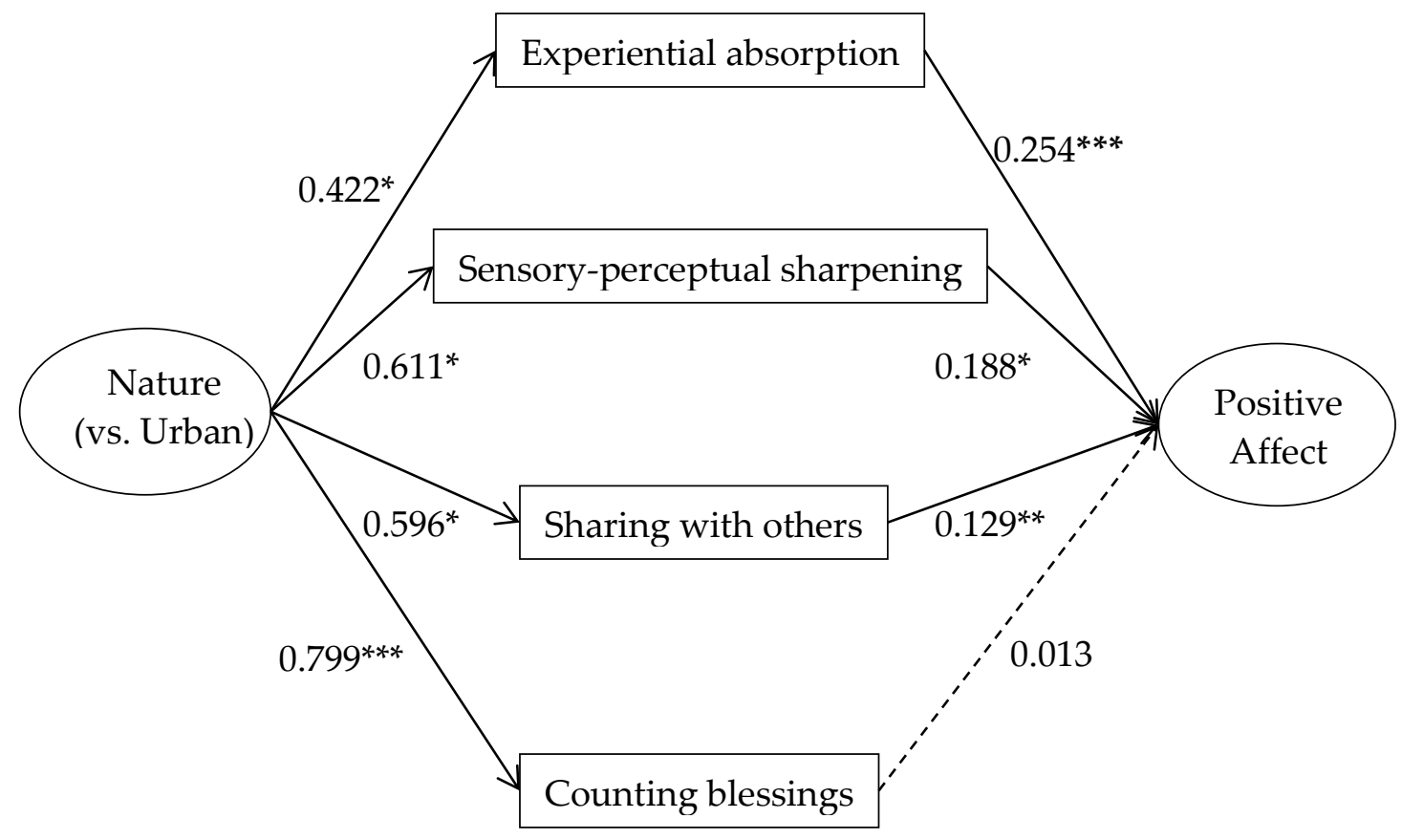

Note. Unstandardized path/correlation coefficient; ${ }^{*} p<.05 ;{ }^{* *} p<.01 ;{ }^{* * *} p<.001$.

Lastly, in order to probe the mediation further, we conducted a multilevel mediational analysis with all four savoring items entered simultaneously (experiential absorption, sensory-perceptual sharpening, sharing with others, and counting blessings) to examine the relative importance of these four items for the link between nature and PA. As Figure 4 above shows, three of the savoring items (experiential absorption, sensory-perceptual sharpening, sharing with others) survived as significant mediators of the nature-PA path $(\beta=0.254, p<0.001 ; \beta=0.188, p=0.012$; 
$\beta=0.129, p=0.002$, respectively $)^{1}$. It is noteworthy that counting blessings was no longer significantly associated with PA when all items were entered simultaneously $(\beta=-0.013, p=$ 0.827), even though it predicted greater PA when combined with sharing with others in the previous analysis.

\section{Discussion}

How does the experience of nature improve wellbeing? Our results suggest that savoring is a key element to understanding why people feel happier after spending time in nature. People who were randomly assigned to walk 20 minutes in nature (versus 20 minutes in an urban environment) reported significantly increased savoring behaviors, which, in turn, predicted increased feelings of positive affect. Of the four individual savoring items, experiential absorption, sensory-perceptual sharpening, and sharing with others stood out as the strongest mediators of the nature to PA link. These results suggest that increased PA is most strongly tied to absorbing oneself in nature, trying to intensify experiences in nature, and sharing the positive aspects of nature experiences with other people.

These findings could be interpreted to suggest that nature may promote an "inner savoring tendency" which has an enhancing effect on positive emotion. Natural environments not only provide an opportunity for experiencing happiness per se, but they could also evoke processes of prolonging this experience. According to the principles of biophilia (Wilson, 1984), evolutionary influences over the millennia might have predisposed human interactions with nature to have an adaptive and positive value for human survival. Although this may sound highly speculative, it might be possible that evolution could have selected for processes in the human mind that not only enhance pleasure while in nature, but also encourage a return to nature through behavioral strategies for prolonging and maximizing pleasure, which is the very definition of savoring (Bryant \& Veroff, 2007). As this study demonstrated, natural environments, more than urban environments, seemed to evoke a tendency towards all four types of savoring strategies, including greater perceptual engagement (experiential absorption/sensory-perceptual sharpening), counting blessings, and sharing with others. Urban environments evoked no savoring strategies.

This study did not find a significant total effect of nature on PA $(r=.083$, as shown in Table 3 above). This finding is not consistent with the bulk of prior research, which regularly finds that exposure to nature increases PA (e.g., McMahan \& Estes, 2015). For example, past research that has shown that viewing nature images results in increased PA in lab settings (van den Berg, Koole, \& van der Wulp, 2003), that proximity to nature results in higher PA (Stigsdotter et al., 2010), and that walking in natural environments results in more PA than walking in urban environments (Hartig et al., 2003). Moreover, a recent meta-analysis found stronger links between nature interventions on changes in PA than NA (McMahan \& Estes, 2015). The inconsistency with previous studies may be due to the way PA was measured in the present study. In our study, PA was measured at the end of the day, not the moment when participants finished the walk. This methodological choice was a limitation. Nonetheless, this limitation was addressed by applying appropriately sophisticated tools for testing mediation that did not require a significant total effect and by focusing the pathway of influence (i.e., indirect effect). Another possible reason for the non-significant total effect of nature on PA could be the specific items used to measure PA: excited, happy, and relaxed. There may have been too few items or

\footnotetext{
${ }^{1}$ All four savoring items were correlated with each other moderately to strongly (within the range of .446 to .642, all significant).
} 
the items were not tapping the right type of positive affect. Perhaps if we had used the Positive and Negative Affect Schedule (PANAS) (Watson, Clark, \& Tellegen, 1988), which taps positive activation, this would have resulted in significant findings. Future research should take care when selecting the appropriate outcome measure.

This study also found no unique effect of gratitude (counting blessings) on improvements in PA. Although walking in nature increased feelings of gratitude ("I felt grateful for the event"), these feelings did not mediate the link to PA. This finding is inconsistent with prior research on gratitude, which is one of the key positive psychology intervention strategies shown to effectively increase wellbeing (Bolier et al., 2013). Moreover, in the brief intervention by Richardson and Sheffield (2017), participants randomly assigned to write about blessings in nature showed benefits to mental health. This inconsistency might be due to the fact that counting blessings was very highly correlated with the other savoring strategies (i.e., $r \mathrm{~s} 0.466$ to 0.563), so when entered simultaneously with the other savoring strategies, counting blessings was no longer a significant predictor of PA. It is also possible that nature influences PA through more primitive and perceptual forms of savoring (i.e., experiential absorption and perceptual sharpening), as opposed to more sophisticated cognitive forms of savoring (i.e., counting blessings); however, we are not confident with this interpretation, since the double mediation path model of Figure 3 above suggested that primitive and perceptual forms of savoring during the walk only predicted positive affect through effects on savoring after the walk. Further investigation is needed to clarify the issue.

The study had several limitations. As mentioned above, one limitation is that the PA measure was taken only at the end of the day, and with a relatively wide timeframe (how they felt "that day"). Thus, PA reflected a summary judgment of participants' entire day. This timeframe may have introduced more error and less sensitivity, making it harder to detect the exact temporal relationship between the predictor (savoring) and the outcome (PA). Similarly, people were asked to retrospect on their experiences of savoring "during the walk" at the end of the day, which would be less accurate than asking immediately after the walk. However, according to Parkinson and his colleagues (Parkinson, Briner, Reynolds, \& Totterdell, 1995), end-of-day retrospective reports are reasonably accurate, suggesting that memory bias in this study was tolerable. Further studies need to address these temporal measurement issues, possibly using experience sampling methods to track the dynamics of real-time experiences throughout the day, taking care not to disrupt attention during the nature walk, which could take people out of the moment. Another limitation was the relatively small sample size $(\mathrm{N}=60)$. Although sample sizes of 60 are common in daily diary designs (e.g., N=54 (Affleck, Tennen, Urrows, \& Higgins, 1992); $\mathrm{N}=70$ (Rost et al., 2016)), it is possible that our sample size was somewhat underpowered. We conducted a post-hoc power analysis for multi-level research by using The Optimal Design Software (Raudenbush, Spybrook, Congdon, Liu, \& Martinez, 2011) and found our study needed 74 people to detect a small effect size of .25 with .80 power. Thus, a larger sample would have potentially improved sensitivity to detect smaller effects in the data. For example, with more participants, the nature (vs. urban) condition might have yielded a significant total effect on PA.

\section{Conclusion}

The most important finding of this study was the discovery of savoring as an emotion regulation strategy that mediated the effect of natural environments on positive affect. This finding suggests that nature can enrich humans' everyday emotional lives via its effect on emotional savoring, in particular, strategies such as absorbing and intensifying experiences in nature, and sharing nature experiences with others. Importantly, through an experimental design, we showed these 
inner savoring tendencies are evoked in natural environments, not urban environments, which suggests an important connection between nature and positive emotion regulation.

\author{
Authors \\ Izuru Sato \\ University of Otago \\ Paul E. Jose \\ Victoria University of Wellington \\ Tamlin S. Conner \\ University of Otago \\ tconner@psy.otago.ac.nz

\section{Publishing Timeline} \\ Received 12 April 2017 \\ Accepted 7 January 2018 \\ Published 13 July 2018
}

\title{
References
}

Affleck, G., Tennen, H., Urrows, S., \& Higgins, P. (1992). Neuroticism and the pain-mood relation in rheumatoid arthritis: Insights from a prospective daily study. Journal of Consulting and Clinical Psychology, 60(1), 119-126. https://doi.org/10.1037/0022-006X.60.1.119

Baron, R. M., \& Kenny, D. A. (1986). The moderator-mediator variable distinction in social psychological research: Conceptual, strategic, and statistical considerations. Journal of Personality and Social Psychology, 51(6), 1173-1182. https://doi.org/10.1037/0022-3514.51.6.1173

Barrett, L. F, \& Russell, J. A. (1998). Independence and bipolarity in the structure of current affect. Journal of Personality and Social Psychology, 74, 967-984. https://doi.org/10.1037/0022-3514.74.4.967

Barton, J., \& Pretty, J. (2010). What is the best dose of nature and green exercise for improving mental health? A multi-study analysis. Environmental Science \& Technology, 44(10), 3947-3955. https://doi.org/10.1021/es903183r

Berto, R. (2005). Exposure to restorative environments helps restore attentional capacity. Journal of Environmental Psychology, 25(3), 249-259. https://doi.org/10.1016/j.jenvp.2005.07.001

Berto, R. (2014). The role of nature in coping with psycho-physiological stress: A literature review on restorativeness. Behavioral Sciences, 4(4), 394-409. https://doi.org/10.3390/bs4040394

Bolier, L., Haverman, M., Westerhof, G. J., Riper, H., Smit, F., \& Bohlmeijer, E. T. (2013). Positive psychology interventions: A meta-analysis of randomized controlled studies. BMC Public Health, 13(1), 119-139. https://doi.org/10.1186/1471-2458-13-119

Bowler, D. E., Buyung-Ali, L. M., Knight, T. M., \& Pullin, A. S. (2010). A systematic review of evidence for the added benefits to health of exposure to natural environments. BMC Public Health, 10(1), 456465. https://doi.org/10.1186/1471-2458-10-456

Bratman, G. N., Daily, G. C., Levy, B. J., \& Gross, J. J. (2015). The benefits of nature experience: Improved affect and cognition. Landscape and Urban Planning, 138, 41-50. https://doi.org/10.1016/j.landurbplan.2015.02.005

Bryant, F. B, Chadwick, E. D, \& Kluwe, K. (2011). Understanding the processes that regulate positive emotional experience: Unsolved problems and future directions for theory and research on savoring. International Journal of Wellbeing, 1(1), 107-126. https://doi.org/10.5502/ijw.v1i1.18

Bryant, F. B., \& Smith, J. L. (2015). Appreciating life in the midst of adversity: Savoring in relation to mindfulness, reappraisal, and meaning. Psychological Inquiry, 26(4), 315-321.

https://doi.org/10.1080/1047840x.2015.1075351 
Bryant, F. B., \& Veroff, J. (2007). Savoring: A new model of positive experience. Mahwah, NJ: Lawrence Erlbaum.

Card, N. A. (2012). Multilevel mediational analysis in the study of daily lives. In M. R. Mehl \& T. S. Conner (Eds.), Handbook of research methods for studying daily life (pp. 479-494). New York, NY: Guilford Press.

Frumkin, P. (2001). Beyond toxicity: Human health and the natural environment. American Journal of Preventive Medicine, 20(3), 234-240. https://doi.org/10.1016/S0749-3797(00)00317-2

Geldhof, G. J., Preacher, K. J., \& Zyphur, M. J. (2014). Reliability estimation in a multilevel confirmatory factor analysis framework. Psychological Methods, 19(1), 72-91. https://doi.org/10.1037/a0032138

Gentzler, A. L., Palmer, C. A., \& Ramsey, M. A. (2015). Savoring with intent: Investigating types of and motives for responses to positive events. Journal of Happiness Studies, 17(3), 937-950. https://doi.org/10.1007/s10902-015-9625-9

Goldberg, D. P., \& Hillier, V. F. (1979). A scaled version of the General Health Questionnaire. Psychological Medicine, 9(1), 139-145. https://doi.org/10.1017/S0033291700021644

Grahn, P., \& Stigsdotter, U. A. (2003). Landscape planning and stress. Urban Forestry \& Urban Greening, 2(1), 1-18. https://doi.org/10.1078/1618-8667-00019

Gross, J. (2015). Emotion regulation: Current status and future prospects. Psychological Inquiry, 26(1), 1-26. https://doi.org/10.1080/1047840X.2014.940781

Gross, J., \& Thompson, R. A. (2007). Emotion regulation: Conceptual foundations. In J. J. Gross (Ed.), Handbook of emotion regulation (pp. 3-24). New York, NY: Guilford Press.

Hartig, T., Evans, G. W., Jamner, L. D., Davis, D. S., \& Garling, T. (2003). Tracking restoration in natural and urban field settings. Journal of Environmental Psychology, 23(2), 109-123. https://doi.org/10.1016/s0272-4944(02)00109-3

Johnsen, S. Å. K., \& Rydstedt, L. W. (2013). Active use of the natural environment for emotion regulation. Europe's Journal of Psychology, 9(4), 798-819. https://doi.org/10.5964/ejop.v9i4.633

Jose, P. E. (2013). Doing statistical mediation and moderation. New York, NY: Guilford Press.

Jose, P. E., Lim, B. T., \& Bryant, F. B. (2012). Does savoring increase happiness? A daily diary study. Journal of Positive Psychology, 7(3), 176-187. https://doi.org/10.1080/17439760.2012.671345

Joye, Y., \& van den Berg, A. (2011). Is love for green in our genes? A critical analysis of evolutionary assumptions in restorative environments research. Urban Forestry \& Urban Greening, 10(4), 261-268. https://doi.org/10.1016/j.ufug.2011.07.004

Kaplan, R., \& Kaplan, S. (1989). The experience of nature: A psychological perspective. Cambridge, England: Cambridge University Press.

Kaplan, S. (1995). The restorative benefits of nature: Toward an integrative framework. Journal of Environmental Psychology, 15(3), 169-182. https://doi.org/10.1016/0272-4944(95)90001-2

Kellert, S. R., \& Wilson, E. O. (1995). The biophilia hypothesis. Washington, D.C.: Island Press.

Kline, R. B. (2011). Principles and practice of structural equation modeling (3rd ed.). New York, NY: Guilford Press.

Korpela, K. M., Hartig, T., Kaiser, F. G., \& Fuhrer, U. (2001). Restorative experience and self-regulation in favorite places. Environment and Behavior, 33(4), 572-589. https://doi.org/10.1177/00139160121973133

Korpela, K. M., Ylen, M., Tyrvainen, L., \& Silvennoinen, H. (2010). Favorite green, waterside and urban environments, restorative experiences and perceived health in Finland. Health Promotion International, 25(2), 200-209. https://doi.org/10.1093/heapro/daq007

Kuo, M. (2015). How might contact with nature promote human health? Exploring promising mechanisms and a possible central pathway. Frontiers in Psychology, 6. https://doi.org/10.3389/fpsyg.2015.01093

Lazarus, R. S., \& Folkman, S. (1984). Stress, appraisal, and coping. New York, NY: Springer.

MacKerron, G., \& Mourato, S. (2013). Happiness is greater in natural environments. Global Environmental Change-Human and Policy Dimensions, 23(5), 992-1000. https://doi.org/10.1016/j.gloenvcha.2013.03.010

MacKinnon, D. P., \& Fairchild, A. J. (2009). Current directions in mediation analysis. Current Directions in Psychological Science, 18(1), 16-20. https://doi.org/10.1111/j.1467-8721.2009.01598.x 
Maller, C., Townsend, M., Pryor, A., Brown, P., \& St Leger, L. (2006). Healthy nature healthy people: 'Contact with nature' as an upstream health promotion intervention for populations. Health Promotion International, 21(1), 45-54. https://doi.org/10.1093/heapro/dai032

McMahan, E. A., \& Estes, D. (2015). The effect of contact with natural environments on positive and negative affect: A meta-analysis. The Journal of Positive Psychology, 10(6), 507-519. https://doi.org/10.1080/17439760.2014.994224

Muthén, B. O., \& Muthén, L. K. (2012). Mplus user's guide. (7th ed). Los Angeles, CA: Muthén \& Muthén.

Parkinson, B., Briner, R. B., Reynolds, S., \& Totterdell, P. (1995). Time frames for mood: Relations between momentary and generalized ratings of affect. Personality and Social Psychology Bulletin, 21(4), 331-339. https://doi.org/10.1177/0146167295214003

Pasanen, T. P., Neuvonen, M., \& Korpela, K. M. (2017). The psychology of recent nature visits: (How) are motives and attentional focus related to post-visit restorative experiences, creativity, and emotional well-being? Environment and Behavior. https://doi.org/10.1177/0013916517720261

Passmore, H. A., \& Howell, A. J. (2014). Nature involvement increases hedonic and eudaimonic wellbeing: A two-week experimental study. Ecopsychology, 6(3), 148-154.

Preacher, K. J. (2015). Advances in mediation analysis: A survey and synthesis of new developments. In S. T. Fiske (Ed.), Annual Review of Psychology (vol. 66, pp. 825-852). Palo Alto, CA: Annual Reviews. https://doi.org/10.1146/annurev-psych-010814-015258

Preacher, K. J., Zhang, Z., \& Zyphur, M. J. (2011). Alternative methods for assessing mediation in multilevel data: The advantages of multilevel SEM. Structural Equation Modeling, 18(2), 161-182. https://doi.org/10.1080/10705511.2011.557329

Preacher, K. J., Zyphur, M. J., \& Zhang, Z. (2010). A general multilevel SEM framework for assessing multilevel mediation. Psychological Methods, 15(3), 209-233. https://doi.org/10.1037/a0020141

Quoidbach, J., Berry, E. V., Hansenne, M., \& Mikolajczak, M. (2010). Positive emotion regulation and well-being: Comparing the impact of eight savoring and dampening strategies. Personality and Individual Differences, 49(5), 368-373. https://doi.org/10.1016/j.paid.2010.03.048

Quoidbach, J., Mikolajczak, M., \& Gross, J. J. (2015). Positive interventions: An emotion regulation perspective. Psychological Bulletin, 141(3), 655-693. https://doi.org/10.1037/a0038648

Raudenbush, S. W., Spybrook, J., Congdon, R., Liu, X. F., \& Martinez, A. (2011). Optimal Design Software for Multi-level and Longitudinal Research (Version 3.01) [Computer Software].

Richardson, M., \& Sheffield, D. (2017). Three good things in nature: Noticing nearby nature brings sustained increases in connection with nature / Tres cosas buenas de la naturaleza: prestar atención a la naturaleza cercana produce incrementos prolongados en conexión con la naturaleza. Bilingual Journal of Environmental Psychology, 8(1), 1-32. https://doi.org/10.1080/21711976.2016.1267136

Rost, S., Van Ryckeghem, D. M., Koval, P., Sütterlin, S., Vögele, C., \& Crombez, G. (2016). Affective instability in patients with chronic pain: A diary approach. Pain, 157(8), 1783-1790. https://doi.org/10.1097/j.pain.0000000000000582

Sato, I., \& Conner, T. S. (2013). The quality of time in nature: How fascination explains and enhances the relationship between nature experiences and daily affect. Ecopsychology, 5(3), 197-204. https://doi.org/10.1089/eco.2013.0026

Sobel, M. E. (1982). Asymptotic confidence intervals for indirect effects in structural equation models. In S. Leinhardt (Ed.), Sociological methodology (pp. 290-312). Washington DC: American Sociological Association. https://doi.org/10.2307/270723

Spehar, B., Clifford, C. W. G., Newell, B. R., \& Taylor, R. P. (2003). Universal aesthetic of fractals. Computers E Graphics, 27(5), 813-820. https://doi.org/10.1016/S0097-8493(03)00154-7

Spehar, B., \& Taylor, R. P. (2013, March). Fractals in art and nature: Why do we like them? Paper presented at the Proceedings of the SPIE 8651, Human Vision and Electronic Imaging XVIII, 865118.

Stigsdotter, U. K., Ekholm, O., Schipperijn, J., Toftager, M., Kamper-Jorgensen, F., \& Randrup, T. B. (2010). Health promoting outdoor environments: Associations between green space, and health, health-related quality of life and stress based on a Danish national representative survey. Scandinavian Journal of Public Health, 38(4), 411-417. https://doi.org/10.1177/1403494810367468 
van den Berg, A. E., Joye, Y., \& Koole, S. L. (2016). Why viewing nature is more fascinating and restorative than viewing buildings: A closer look at perceived complexity. Urban Forestry $\mathcal{E}$ Urban Greening, 20, 397-401. https://doi.org/10.1016/j.ufug.2016.10.011

van den Berg, A. E., Koole, S. L., \& van der Wulp, N. Y. (2003). Environmental preference and restoration: (How) are they related? Journal of Environmental Psychology, 23(2), 135-146. https://doi.org/10.1016/s0272-4944(02)00111-1

Watson, D., Clark, L. A., \& Tellegen, A. (1988). Development and validation of brief measures of positive and negative affect: The PANAS scales. Journal of Personality and Social Psychology, 54(6), 1063-1070. https://doi.org/10.1037/0022-3514.54.6.1063

Wilson, E. (1984). Biophilia: The human bond with other species. Cambridge, MA: Harvard University Press. 